\title{
Development of custom measurement system for biomechanical evaluation of independent wheelchair transfers
}

\author{
Alicia M. Koontz, PhD, RET; ${ }^{1-3 *}$ Yen-Sheng Lin, MS; ${ }^{1,3}$ Padmaja Kankipati, MS; ${ }^{1,3}$ Michael L. Boninger, \\ $\mathrm{MD}^{1-4}$ Rory A. Cooper, PhD $^{1-4}$ \\ ${ }^{1}$ Human Engineering Research Laboratories, Department of Veterans Affairs Pittsburgh Healthcare System, Pitts- \\ burgh, PA; Departments of ${ }^{2}$ Bioengineering; ${ }^{3}$ Rehabilitation Science and Technology, and ${ }^{4}$ Physical Medicine and \\ Rehabilitation, University of Pittsburgh, Pittsburgh, PA
}

\begin{abstract}
This study describes a new custom measurement system designed to investigate the biomechanics of sitting-pivot wheelchair transfers and assesses the reliability of selected biomechanical variables. Variables assessed include horizontal and vertical reaction forces underneath both hands and threedimensional trunk, shoulder, and elbow range of motion. We examined the reliability of these measures between 5 consecutive transfer trials for 5 subjects with spinal cord injury and 12 nondisabled subjects while they performed a self-selected sitting pivot transfer from a wheelchair to a level bench. A majority of the biomechanical variables demonstrated moderate to excellent reliability $(r>0.6)$. The transfer measurement system recorded reliable and valid biomechanical data for future studies of sittingpivot wheelchair transfers. We recommend a minimum of five transfer trials to obtain a reliable measure of transfer technique for future studies.
\end{abstract}

Key words: activities of daily living, assessment, forces, kinematics, kinetics, range of motion, reliability, spinal cord injury, three-dimensional motion analysis, upper limb.

\section{INTRODUCTION}

Individuals with spinal cord injury (SCI) rely on their upper limbs for activities of daily living (ADLs) such as wheelchair propulsion, pressure relief, and transfers from a wheelchair to another surface. These ADLs have been associated with a high prevalence of upper-limb pain and injury reported among individuals with SCI [1]. The onset of pain or an overuse injury can be devastating, leading to increased healthcare expenses, limitations on activity, depression, decreased societal participation, and a reduced quality of life [2]. Although transfers are essential for daily living and are ranked among the most strenuous wheelchair-related activities [3-4], research on the biomechanics of transfers is surprisingly sparse.

Existing biomechanical studies on independent transfers have been descriptive, investigating movement strategies [5-9]; muscular demand [7,10-12]; internal joint pressures [3]; and hand, buttock, and feet reaction forces [11,13-15] for transfers between two-level or nonlevel surfaces among nondisabled and individuals mainly with SCI. Very few studies have reported synchronized kinetics and kinematics during transfers [14-16], and only one

\footnotetext{
Abbreviations: $3-\mathrm{D}=$ three-dimensional, $\mathrm{ADL}=$ activity of daily living, $\mathrm{BW}=$ body weight, $\mathrm{ICC}=$ intraclass correlation coefficient, IRB = institutional review board, $\mathrm{L}=$ lumbar, $\mathrm{SCI}=$ spinal cord injury, $\mathrm{SD}=$ standard deviation, $\mathrm{T}=$ thoracic, $\mathrm{VA}=$ Department of Veterans Affairs.

*Address all correspondence to Alicia M. Koo ntz, PhD, RET; Human Engineering Research Laboratories (151R1H), VA Pittsburgh Healthcare System, 7180 Highland Dr, 151R1-H, Pittsburgh, PA 15206; 412-954-5280; fax: 412954-5340. Email: akoontz@pitt.edu

DOI:10.1682/JRRD.2010.09.0169
} 
research group to date has reported upper-limb inverse dynamics for a sitting-pivot (also referred to in the literature as lateral, depression, or side approach) transfer $[9,17]$. Forslund et al. measured transfers with subjects moving to a force plate on a table next to their wheelchair [15]. Two additional force plates, one on the table and one on the other side of the wheelchair, recorded the trailing and leading hand forces, respectively. Tanimoto et al.'s setup incorporated four force plates to measure the forces underneath both feet, the wheelchair, the leading arm, and the buttocks [14]. Gagnon et al. developed a transfer measurement system incorporating five force plates and force-sensing platforms to measure the leading arm, trailing arm, buttocks under the initial surface, buttocks under the target surface, and feet forces during transfer [16]. Tanimoto et al.'s setup synchronized the kinetics of transfer with two-dimensional motion capture, while the other two systems synchronized kinetics with three-dimensional (3-D) motion capture systems [14].

None of the authors in these previous studies reported on the reliability or repeatability of the data collected with their experimental setup. Thus, assessing how well subjects acclimated to the novelty of the setup and how consistent they were in executing the transfer from trial to trial is difficult. A reliability assessment also provides insight into the number of trials necessary to obtain a stable measure of an individual's movement strategies during functional tasks [18-20].

All the aforementioned systems, while advancing the body of knowledge about strategies used and the mechanics of performing transfers, have one or more of the following limitations: (1) the actual wheelchair is not part of the transfer process [16]; (2) trailing and leading hand forces, which have shown differing kinetic, kinematics and muscular demands [12], are not recorded simultaneously [14]; (3) orientation of the wheelchair/ surface of origin is fixed in relation to the surface a subject is transferring to/from [15-16]; and (4) the system requires that both hands be placed on a flat surface for kinetics to be recorded [14-16]. We designed our transfer measurement system to address these shortcomings and to include other features we believe are critical to understanding the mechanical demands of transfers. This study (1) describes a new custom measurement system to investigate the biomechanics of sitting-pivot wheelchair transfers and (2) evaluates the reliability of shoulder, elbow, and trunk ranges of motion and hand reaction forces in a naïve nondisabled group of subjects and an experienced group of subjects with SCI.

\section{METHODS}

\section{Transfer Measurement System}

The design criteria for our system included the following:

- Employ synchronized recording of 3-D upper-limb kinematics and kinetics during the transfer process.

- Include the personal wheelchair as a surface in the transfer process.

- Allow for fixed and variable wheelchair orientation with respect to the target surface.

- Enable evaluation of different target surfaces.

- Incorporate a load-sensing beam adjustable in height and location to allow for evaluating transfers where a hand grasp may be used.

\section{Kinetics Measurement}

The general setup for collecting the kinetics of transfers consists of a custom-designed base frame, two aluminum mounting plates attached to two force plates, and a load-sensing beam (Figure 1). The base frame is made of $10.2 \mathrm{~cm}$ steel C-channel, welded to create two $2,800 \mathrm{~cm}^{2}$ compartments. Each compartment houses a custom aluminum mounting plate with threaded holes at equal intervals to allow for interchanging and securing different types of transfer surfaces (e.g., commode, vehicle seat, or transfer bench). The plate is bolted to a force plate (model FP4550-08, Bertec Corporation; Columbus, Ohio) (Figure 1) and secured to a level concrete floor. The wheelchair and transfer surfaces are secured to the mounting plates with custom-designed brackets.

We designed a custom interface composed of 6061 aluminum to securely affix a curved $2.54 \mathrm{~cm}$-diameter steel tube to a six-component load cell (model MC5, Advanced Mechanical Technology, Inc; Watertown, Massachusetts) (Figure 1). The interface bolts directly to the top of the load cell and has a $10.2 \mathrm{~cm}$-deep hollowed center with a bore that allows for close tolerance with the beam. A split collar tightens around the beam with screws, creating a solid, tight fit. The collar design allows for interchanging beams of various heights to simulate different scenarios such as transferring with the arm overhead (e.g., in the case of trapeze or vehicle transfer) or with the hand on a wheelchair armrest as shown in 
(a)

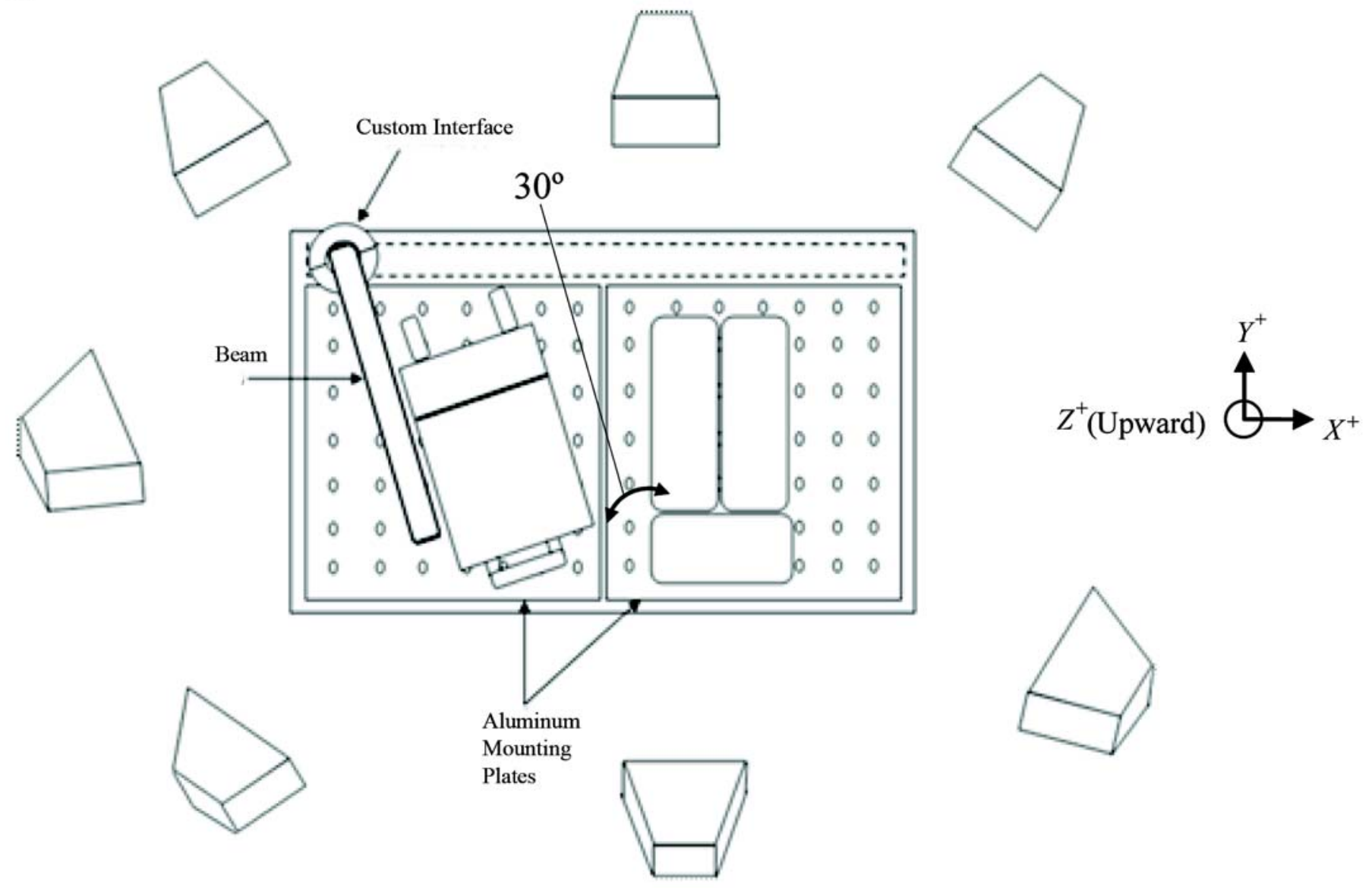

(b)
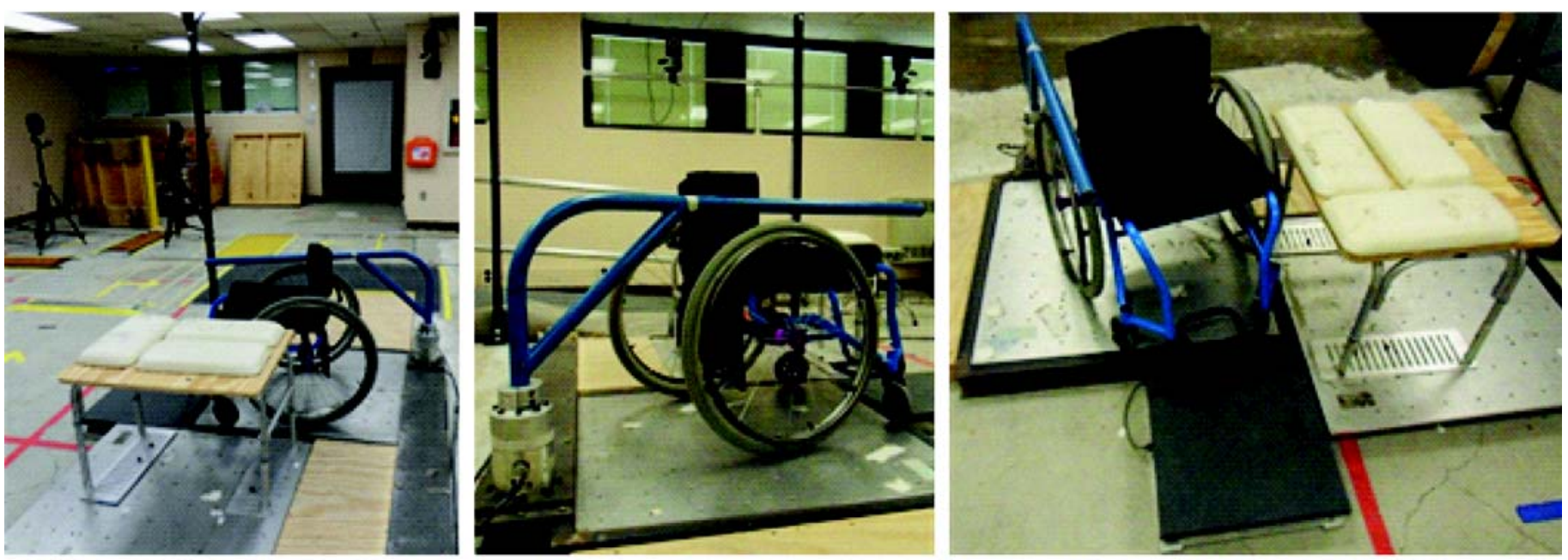

Figure 1.

Wheelchair and bench shown secured to aluminum mounting plates of base frame: (a) schematic and (b) photographs of actual setup. Custom interface consists of load cell and beam of varying heights that can be positioned anywhere along base frame. Seven motion cameras surrounded base frame. Note that kinetic results were presented in laboratory coordinate system, while kinematic results were reported according to International Society of Biomechanics recommendations (left arm, positive $x$ points anteriorly, positive $y$ points superiorly, and positive $z$ points medially). 
Figure 1. Bolted directly to the bottom of the load cell is a square steel plate with threaded holes. On one edge of the base frame is an additional piece of steel C-channel with a $1.59 \mathrm{~cm}$ steel plate bolted to the top with threaded holes at equal intervals, which allow for varying the position of the load cell and beam. We validated frequency analyses of both low and overhead force beams through power spectral density (Appendix 1, available online only). We validated the vertical components of the force plates and the force beam by comparing known weights with the recorded readings. We reset all the force sensors to zero prior to collecting the data to eliminate the system offset. We designed custom components in-house using SolidWorks 2004 (Solid Works Corporation; Concord, Massachusetts) and Feature CAM (Engineering Geometry Systems, Inc; Salt Lake City, Utah). The entire system was fabricated with staff, resources, and equipment available at the Department of Veterans Affairs (VA) Pittsburgh Healthcare System's Human Engineering Research Laboratories.

\section{Kinematics Measurement}

We used a seven-camera 3-D passive motion capture system and Nexus 1.3.110 software (model MX, Vicon Peak; Lake Forest, California) to collect kinematics data during transfer. Following International Society of Biomechanics recommendations, we recorded position data from specified anatomical bony landmarks on the trunk, humerus, and forearm [21]. We positioned the cameras around the base frame to minimize marker drop out (Figure 1). We followed standardized calibration procedures, based on direct linear transformation methods, according to the manufacturer's specifications [22]. We used an L-shape frame with markers to define a global coordinate system in the middle of the two aluminum plates. Redundant markers on each segment ensure that at least three markers are visible for defining local coordinate systems (Appendix 2, available online only). We created a static recording of the markers with the subject's arms held in an anatomical position, with palms facing forward to determine reference local coordinate systems [19]. We synchronized the kinetic measurement devices with the motion capture data through the Vicon MX system.

\section{Subjects}

This study was approved by the VA Pittsburgh Healthcare System Institutional Review Board (IRB). We recruited subjects from an IRB-approved research registry, as well as through flyers and word of mouth. All subjects signed informed consent prior to participation in the study. The inclusion criteria required subjects with SCI to be over the age of 18; use a manual wheelchair as their primary means of mobility; have an SCI between lumbar (L) region L2 and thoracic $(\mathrm{T})$ region T1, American Spinal Injury Association A or B, occurring over 1 year prior to the start of the study; and be able to independently transfer to/from a manual wheelchair without human assistance or assistive devices. The inclusion criteria required nondisabled unimpaired subjects to be able to do a seated push up from a seated position, elevate the torso, and lift the buttocks off the seat using the upper limbs. Self-reported upper-limb pain and/or injury that impaired ability to transfer were exclusion criteria for both groups.

\section{Experimental Protocol}

We used a height-adjustable tub bench as the target surface in this study, adjusted to be level with the height of the wheelchair seat cushion. Nondisabled subjects were seated in an Invacare Top End Terminator ultralight wheelchair (seat $43.2 \mathrm{~cm}$ wide $\times 53.3 \mathrm{~cm}$ high) on top of a $5 \mathrm{~cm}$ high foam cushion. The wheelchair was secured at a $30^{\circ}$ angle from the bench, as shown in Figure 1. Subjects with SCI used their own wheelchairs in the study, which were secured at self-selected angles with respect to the target surface. Before the transfer tasks, we asked subjects to prepare for the transfer as they normally would (e.g., scoot buttocks forward in chair) and to place their hands on their laps before and after completing the transfer. We also instructed subjects to place their left arm on the bench and right arm on the force beam. We requested that the subjects with SCI transfer from their wheelchair to the bench as they would normally if presented with a similar situation in daily life. We asked nondisabled subjects to place their left arm on the bench and right arm on the force beam and move over to the bench while refraining from using leg muscles during the transfer. Each subject transferred from the wheelchair to the bench five times. Subjects took time to orient themselves to the setup (i.e., perform a transfer to/from the wheelchair and bench) prior to data collection and rested in between trials as needed. Kinematic data were collected at $60 \mathrm{~Hz}$ and synchronized with the force data, which were collected at $360 \mathrm{~Hz}$. 


\section{Data Analysis}

The kinematic and kinetic data collected during the wheelchair transfer were smoothed with a fourth-order, zero-lag Butterworth lowpass filter with a cut-off frequency of $10 \mathrm{~Hz}$ [23]. We used customized software (MATLAB 2009b, MathWorks; Natick, Massachusetts) to compute the trunk movement using a Cardan angle sequence (ZXY, along a anterior/posterior axis $[x]$, superior/inferior axis $[y]$, and medial/lateral axis $[z]$ acting to flex/extend $[z]$, lateral rotation $[x]$, and axial rotation $[y]$ with respect to the laboratory coordinate system) and shoulder movement using a Euler angle sequence (YXY along plane of elevation $[y]$, amount of elevation $[x]$, and internal/external rotation $[y]$ for the shoulder coordinate system acting with respect to the trunk coordinate system). Transfers generally consist of three phases: prelift, lift, and postlift phases, based on a review of the literature on transfer biomechanics [12]. Most of the angular displacements and upper-limb loading occur during the lift phase [24]; therefore, we narrowed the scope of our analysis and reporting to this phase of transfer.

We used the vertical reaction forces recorded at the bench force plate and grab bar to determine the start (i.e., sudden force increase at the grab bar and bench side) and end (i.e., prior to buttock impact, which appeared as a large spike in the vertical force component on the bench side) of the lift phase. We identified the maximum and minimum angles of trunk flexion/extension; lateral and axial rotation; shoulder flexion/extension; abduction/ adduction, and internal/external rotation, and elbow flexion/extension as outcome variables in each transfer trial. In addition, we analyzed peak horizontal and vertical hand forces for the leading hand (e.g., reaching to new surface) and trailing hand (e.g., left behind while moving to new location) separately. We downsampled kinetic data to match the sampling frequency of the kinematic data and time-normalized both sets of data to the percentage time of the lift phase.

\section{Statistical Analysis}

We evaluated intrasubject reliability with intraclass correlation coefficients (ICC). We computed ICCs for each variable for transfer trials 3, 4, and 5. A threshold parameter was considered at least moderately reliable if ICC was $>0.6$ [25]. We obtained the mean \pm standard deviation (SD) for each outcome variable by averaging the data over the five trials recorded for the transfer.

\section{RESULTS}

\section{Subjects}

Table 1 shows general subject characteristics for the 5 subjects with SCI and the 12 nondisabled subjects who participated in the study.

\section{Kinetics}

Table 2 shows the group mean \pm SD of the maximum and minimum reaction force components under the hands (leading and trailing). We observed large vertically directed forces $(>29 \%$ body weight $[\mathrm{BW}]$ ) under both hands during the transfer (Figure 2). Horizontal forces were considerably lower $(<16 \% \mathrm{BW})$ than the vertical forces. Horizontal reaction forces at the leading hand were mostly directed posterior and medial and anterior

Table 1.

Group demographics for 5 subjects with SCI and 12 nondisabled subjects performing five transfer trials from wheelchair to level bench.

\begin{tabular}{|c|c|c|c|c|c|}
\hline Subject & Age (yr) & Weight (kg) & Height (m) & $\begin{array}{l}\text { Years with } \\
\text { Injury }\end{array}$ & Level of Injury \\
\hline \multicolumn{6}{|l|}{$\overline{\mathrm{SCI}}(n=5)$} \\
\hline 1 & 38 & 78.9 & 1.7 & 13.3 & $\mathrm{~T} 11-\mathrm{T} 12$ \\
\hline 2 & 33 & 64.0 & 1.7 & 11.5 & T8 \\
\hline 3 & 24 & 99.8 & 2.0 & 5.0 & $\mathrm{~T} 8$ \\
\hline 4 & 47 & 59.0 & 1.8 & 26.5 & $\mathrm{~T} 4$ \\
\hline 5 & 59 & 83.9 & 1.7 & 30.0 & T12-L1 \\
\hline Mean \pm SD & $40.2 \pm 13.4$ & $77.1 \pm 16.3$ & $1.8 \pm 0.1$ & $17.3 \pm 10.6$ & - \\
\hline \multicolumn{6}{|c|}{ Nondisabled $(n=12)$} \\
\hline Mean \pm SD & $27.1 \pm 1.2$ & $79.6 \pm 14.3$ & $1.8 \pm 0.1$ & - & - \\
\hline
\end{tabular}


Table 2.

Group mean \pm standard deviation (SD) peak hand reaction forces normalized to body weight (BW) and intraclass correlation coefficients (ICC) ranges for three, four, and five transfer trials, respectively.

\begin{tabular}{|c|c|c|c|c|}
\hline \multirow{2}{*}{ Peak Hand Reaction Forces } & \multicolumn{2}{|c|}{$\operatorname{SCI}(n=5)$} & \multicolumn{2}{|c|}{ Nondisabled $(n=12)$} \\
\hline & Leading & Trailing & Leading & Trailing \\
\hline \multicolumn{5}{|l|}{$\begin{array}{l}\text { Horizontal }(F x) \text {. Leading: Lat- } \\
\text { eral }(+) \text {, Medial }(-) \text {; Trailing: } \\
\text { Lateral }(-) \text {, Medial }(+)\end{array}$} \\
\hline Max Force \pm SD (\% BW) & $3.61 \pm 5.29$ & $4.48 \pm 3.27$ & $-0.11 \pm 4.25$ & $6.13 \pm 3.72$ \\
\hline ICC Range & $0.91,0.93,0.93$ & $0.96,0.98,0.98$ & $0.90,0.94,0.90$ & $0.96,0.97,0.97$ \\
\hline \multirow{2}{*}{\multicolumn{5}{|c|}{$\begin{array}{l}\text { Horizontal }(F y) \text {. Posterior }(+) \text {, } \\
\text { Anterior }(-)\end{array}$}} \\
\hline & & & & \\
\hline Max Force \pm SD (\% BW) & $6.77 \pm 1.63$ & $-1.91 \pm 2.67$ & $2.19 \pm 2.03$ & $1.48 \pm 5.03$ \\
\hline ICC Range & $0.79,0.81,0.57$ & $0.68,0.51,0.68$ & $0.72,0.82,0.88$ & $0.99,0.99,0.97$ \\
\hline Min Force \pm SD (\% BW) & $-2.93 \pm 2.68$ & $-15.38 \pm 1.57$ & $-4.07 \pm 2.18$ & $-8.26 \pm 5.12$ \\
\hline
\end{tabular}

and medial for the SCI and nondisabled subjects, respectively. Trailing hand reaction forces were directed anterior and medial for both groups. Loading forces at the trailing arm started to decline in the middle of lift phase, while the forces of the leading arm continued to increase until just prior to landing on the target surface (Figure 2). The resultant forces showed similar patterns in both groups. All peak forces showed moderate to excellent agreement with a minimum of three trials (Table 2), except for the peak posterior-anterior force component in the SCI group $(r \geq 0.51)$. ICC values generally increased with trial number.

\section{Kinematics}

Table 3 presents maximum and minimum trunk, shoulder, and elbow angles are presented in Table 3. Shoulder angles for both leading and trailing sides are expressed with respect to the left side coordinate system for ease of interpretation. We observed similar shoulder and elbow movement patterns for the leading and trailing arm in both the SCI and nondisabled groups during the lift phase of transfer (Figures 3 and 4). During the early stage of the lift phase, the leading arm shoulder was extended, abducted, and externally rotated, and the elbow was flexed. Over the course of the lift phase, the leading shoulder was flexed, adducted, and internally rotated, while the elbow was slightly extended but remained flexed. The trailing shoulder started out flexed, abducted, and externally rotated, and the trailing elbow was flexed. As the lift phase progressed, the trailing shoulder extended, abducted, and internally rotated while the elbow extended. We observed increasing trunk flexion, right lateral rotation, and right axial rotation over the course of the lift phase until near the end, at which time the trunk started to extend back toward an upright position prior to landing (Figure 5). The reliability analysis showed that the kinematic variables had moderate to excellent reliability in both leading and trailing arms when all five trials were considered, except for the maximum plane of elevation, maximum elevation, and maximum internal rotation of the trailing shoulder of unimpaired subjects (ICC < 0.6). In general, we found higher reliability coefficients for the group with SCI than for the nondisabled group, and ICC values generally increased with trial number.

\section{DISCUSSION}

We found that our transfer assessment system produced reliable trunk and upper-limb kinetic and kinematic measures during a level sitting-pivot wheelchair 
(a)

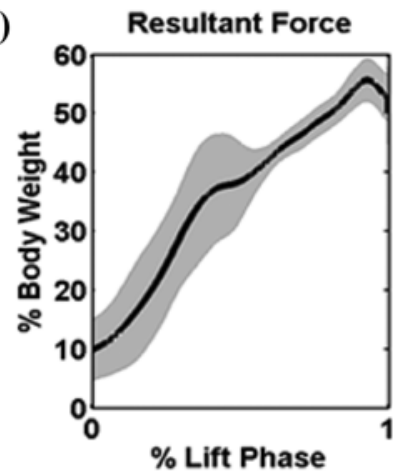

(b)

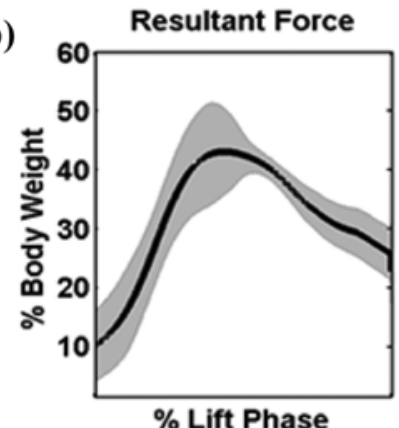

(c)

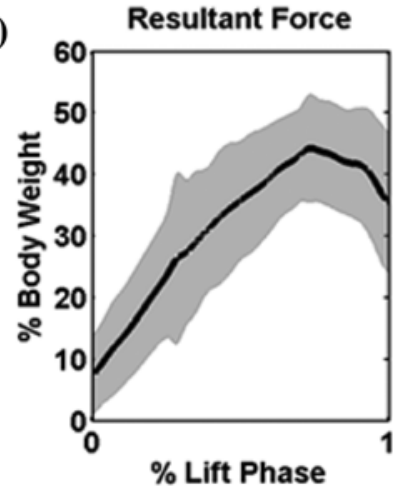

(d)

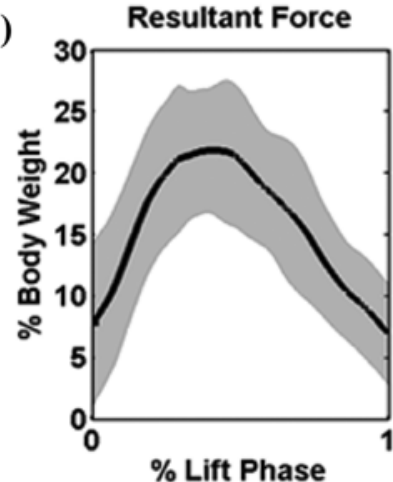

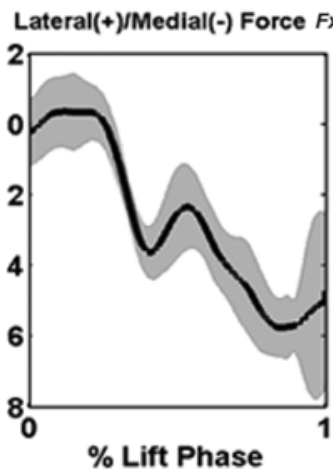

Lateral(-)/Medial(+) Force $F x$

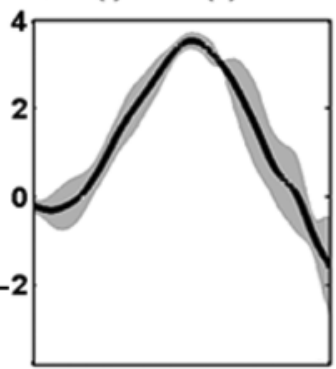

$\%$ Lift Phase

Lateral(+)/Medial(-) Force $F x$

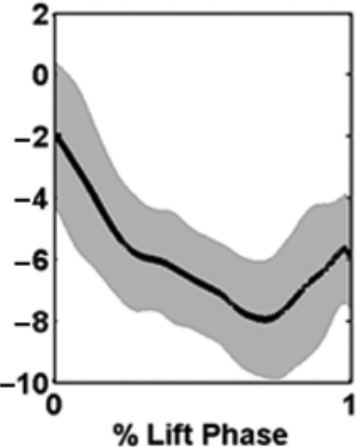

Lateral(-)/Medial(+) Force $F x$

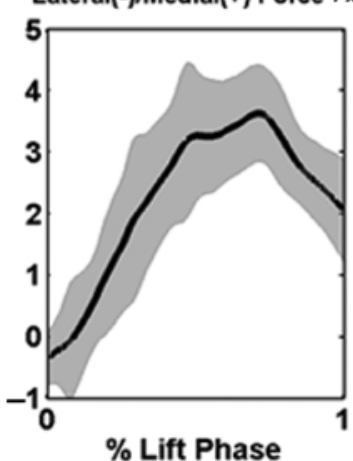

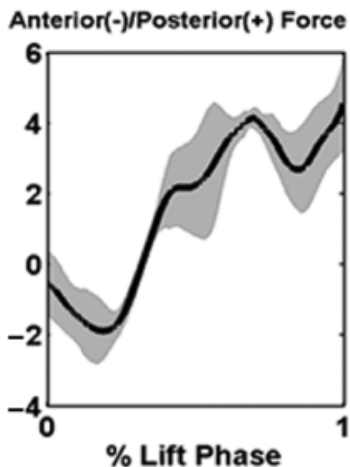

Superior(+)//nferior(-) Force Fz

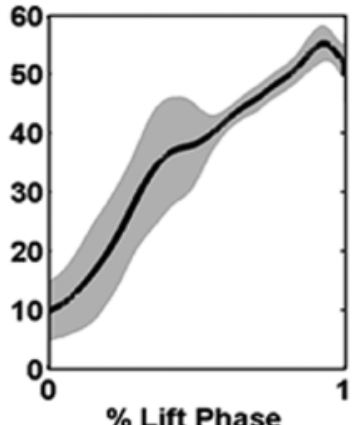

Anterior(-)/Posterior(+) Force Fy Superior(+)/Inferior(-) Force Fz

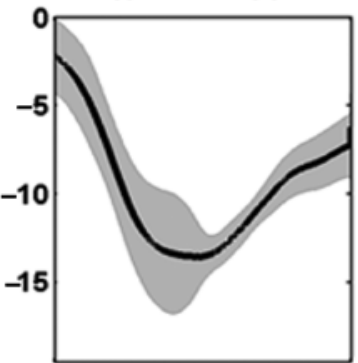

$\%$ Lift Phase
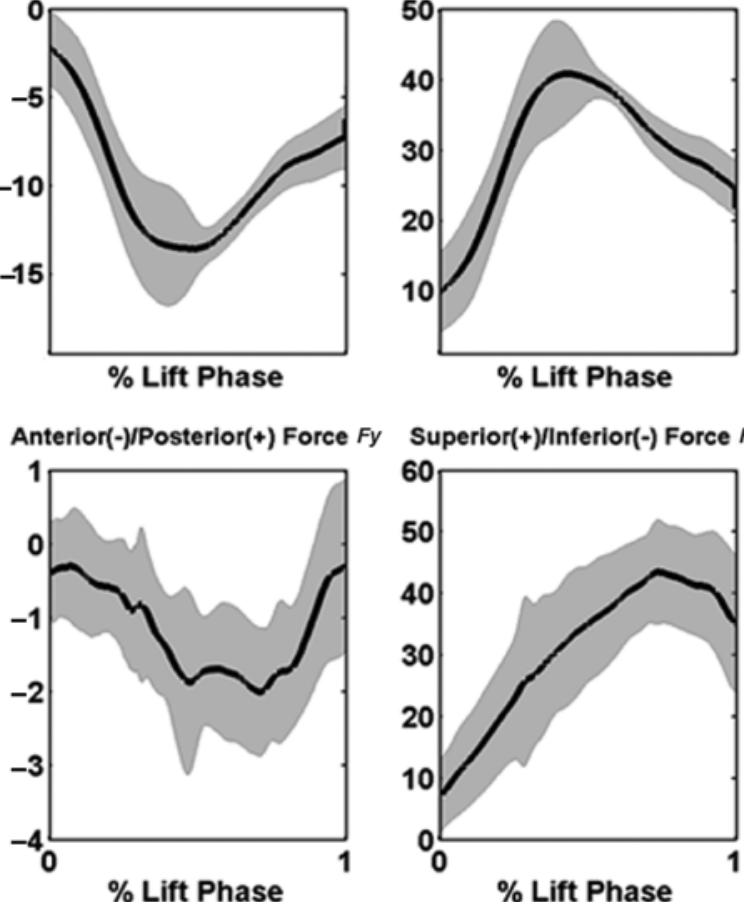

$\%$ Lift Phase

Superior(+)/Inferior(-) Force $F z$

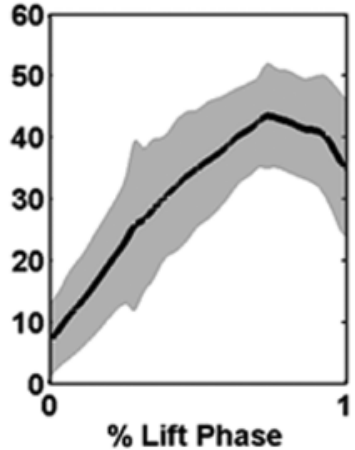

Anterior(-)/Posterior(+) Force Fy Superior(+)/Inferior(-) Force Fz
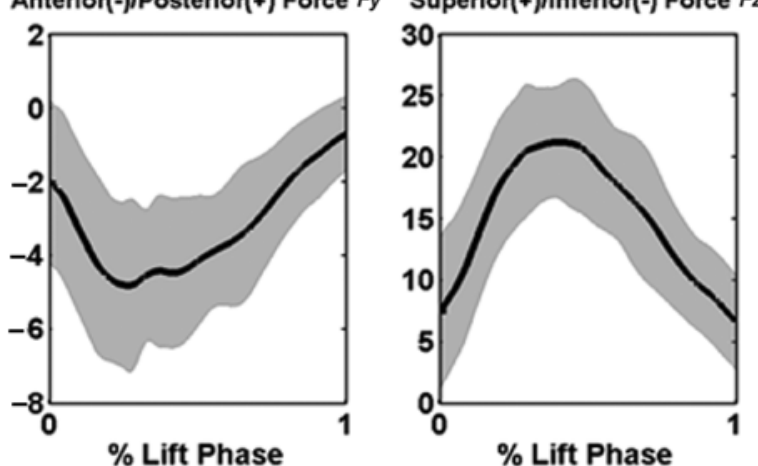

Figure 2.

(a) Leading and (b) trailing hand reaction resultant and $F_{x}, F_{y}$, and $F_{z}$ component forces for all subjects with spinal cord injury $(n=5)$ and (c) leading and (d) trailing hand reaction resultant and component forces for all nondisabled subjects $(n=12)$ during lift phase. Solid lines correspond to group ensemble averages across trials, and shaded areas represent \pm 1 standard deviation. 
Table 3.

Group mean \pm standard deviation of trunk, shoulder, and elbow peak angles $\left(^{\circ}\right)$ and intrasubject correlation coefficient (ICC) ranges for three, four, and five transfer trials, respectively.

\begin{tabular}{|c|c|c|c|c|}
\hline Peak Angles & \multicolumn{2}{|c|}{$\operatorname{SCI}(n=5)$} & \multicolumn{2}{|c|}{ Nondisabled $(n=12)$} \\
\hline \multicolumn{5}{|l|}{ Trunk } \\
\hline ICC Range & \multicolumn{2}{|c|}{$0.78,0.88,0.92$} & \multicolumn{2}{|c|}{$0.62,0.76,0.74$} \\
\hline ICC Range & \multicolumn{2}{|c|}{$0.84,0.91,0.86$} & \multicolumn{2}{|c|}{$0.94,0.95,0.96$} \\
\hline Min Lateral Flexion (Right +) & \multicolumn{2}{|c|}{$-2.24 \pm 5.48$} & \multicolumn{2}{|c|}{$-11.51 \pm 12.09$} \\
\hline ICC Range & \multicolumn{2}{|c|}{$0.94,0.97,0.97$} & \multicolumn{2}{|c|}{$0.96,0.97,0.98$} \\
\hline Min Axial Rotation (Left + ) & \multicolumn{2}{|c|}{$-8.68 \pm 13.15$} & \multicolumn{2}{|c|}{$5.69 \pm 29.23$} \\
\hline ICC Range & \multicolumn{2}{|c|}{$0.98,0.97,0.98$} & \multicolumn{2}{|c|}{$0.92,0.96,0.96$} \\
\hline Shoulder & Leading & Trailing & Leading & Trailing \\
\hline Max Plane of Elevation & $4.89 \pm 21.70$ & $54.62 \pm 16.05$ & $7.78 \pm 10.99$ & $50.08 \pm 8.53$ \\
\hline Max Elevation & $62.08 \pm 11.26$ & $48.85 \pm 5.66$ & $53.57 \pm 10.25$ & $48.49 \pm 4.88$ \\
\hline ICC Range & $0.94,0.95,0.95$ & $0.82,0.91,0.75$ & $0.73,0.85,0.82$ & $0.25,0.33,0.30$ \\
\hline $\operatorname{Max} \operatorname{IR}(-) / \operatorname{ER}(+)$ & $46.58 \pm 10.67$ & $59.10 \pm 15.66$ & $34.56 \pm 13.32$ & $56.73 \pm 9.06$ \\
\hline ICC Range & $0.30,0.67,0.67$ & $0.94,0.97,0.97$ & $0.58,0.69,0.73$ & $0.05,0.31,0.27$ \\
\hline Min IR (-)/ER (+) & $2.29 \pm 24.90$ & $-7.47 \pm 36.72$ & $9.22 \pm 12.88$ & $-12.73 \pm 21.20$ \\
\hline ICC Range & $0.95,0.97,0.97$ & $0.84,0.92,0.94$ & $0.81,0.82,0.81$ & $0.82,0.86,0.87$ \\
\hline \multicolumn{5}{|l|}{ Elbow } \\
\hline Max Flex $(+) / \operatorname{Ext}(-)$ & $53.56 \pm 11.32$ & $46.73 \pm 16.45$ & $51.96 \pm 15.65$ & $34.19 \pm 18.13$ \\
\hline ICC Range & $0.80,0.86,0.81$ & $0.95,0.96,0.96$ & $0.69,0.77,0.80$ & $0.83,0.89,0.90$ \\
\hline Min Flex $(+) / \operatorname{Ext}(-)$ & $26.22 \pm 8.46$ & $19.82 \pm 16.70$ & $26.03 \pm 11.71$ & $3.02 \pm 17.02$ \\
\hline
\end{tabular}

transfer in an experienced group of subjects with SCI and a naïve, nondisabled group of subjects. Our findings are consistent with other studies that have reported the angular displacement patterns of trunk, shoulder, elbow motion, and hand forces among individuals with SCI [7,13-14,16]. This observation, combined with our system checks (e.g., calibration and beam frequency analysis), suggests that the station produces valid measures as well as reliable ones. This is important for future hypothesis testing, for evaluating the effects of new interventions (e.g., transfer training or assistive aids) or advanced therapies and medical treatments (e.g., stem cell implantation or activity-based restorative therapy [26]) on reducing upper-limb joint loading during transfers.

To our knowledge, our system is the only one that allows for recording forces during a transfer when a handgrip is used. Use of the custom force-sensing beam pro- vides for a realistic hand grasp during a transfer. Our station, however, cannot measure grasp on the wheelchair seat frame in lieu of an armrest and, thus, some individuals may have to modify their technique slightly with our station. Another feature we incorporated in our station was the addition of actual surfaces encountered in daily transfers. In our setup, users are not restricted to placing their hand flat on the target surface, because they are not directly contacting a force plate but rather, in this case, a tub bench, for which they could choose to drape their fingers over the edge of the surface. While this provides for a realistic transfer situation, knowing the actual point of force application is difficult, and one must make assumptions to estimate this point (e.g., from markers on the hand) [27].

Transferring from a wheelchair poses different challenges than transferring across two flat adjacent surfaces. 
(a)

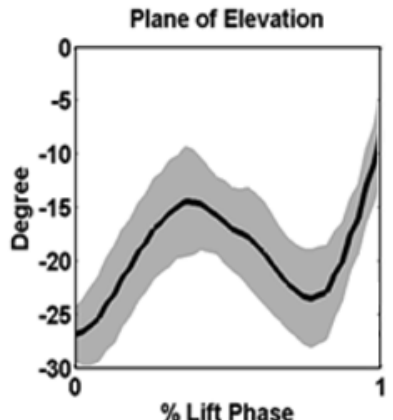

(b)

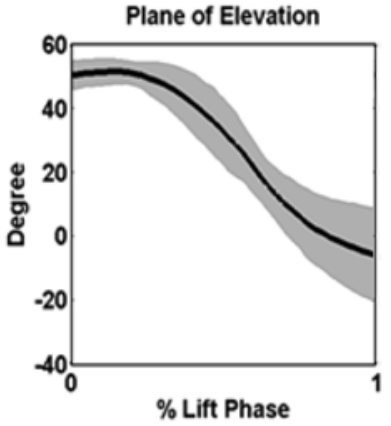

(c)

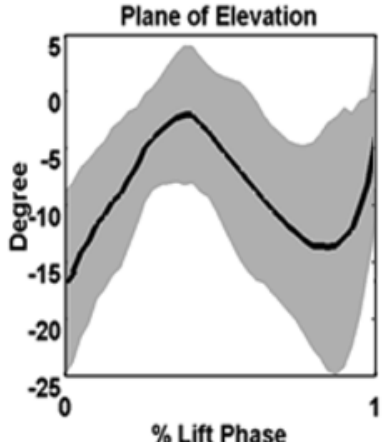

(d)

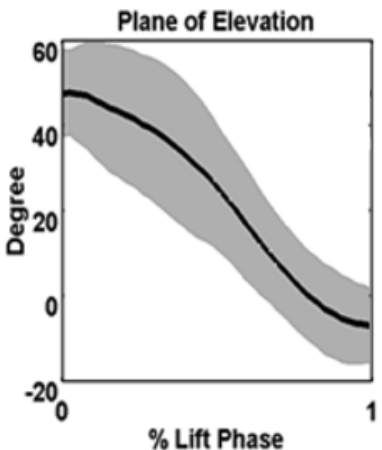

Amount of Elevation
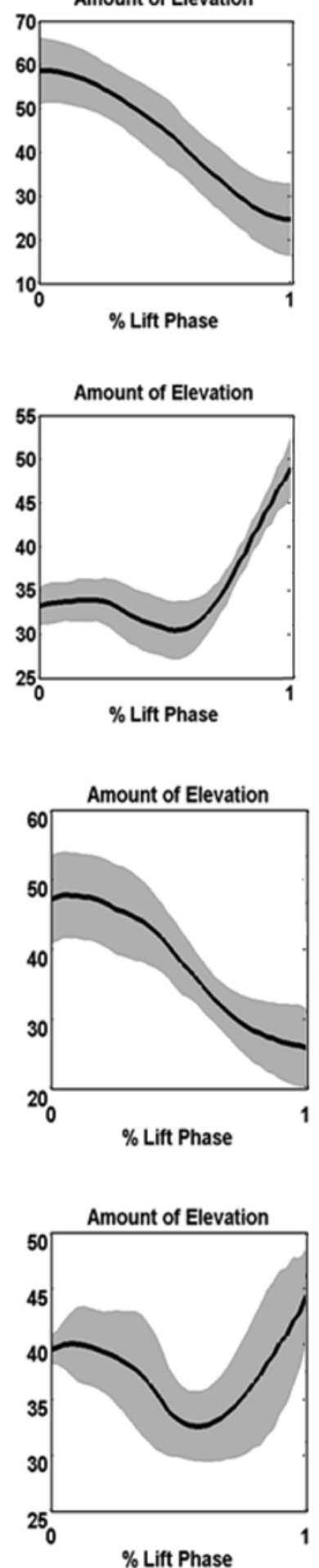
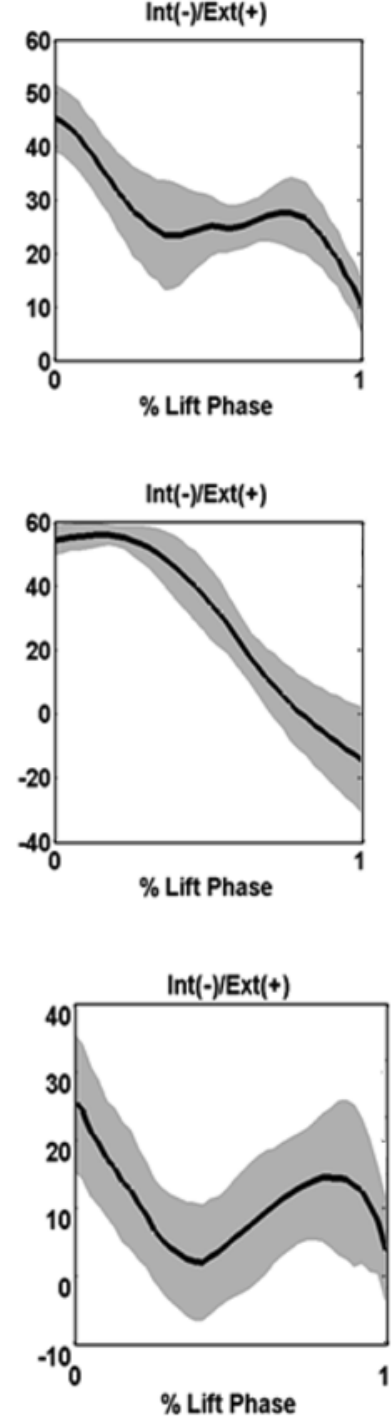

Lift Phase

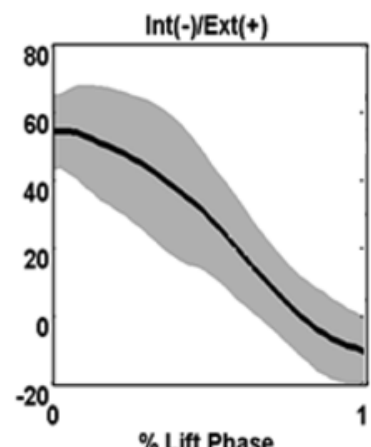

Figure 3.

(a) Leading and (b) trailing shoulder range of motion of all subjects with spinal cord injury and (c) leading and (d) trailing shoulder range of motion of all nondisabled subjects during lift phase of transfer. Solid lines correspond to group ensemble averages across trials, and shaded areas represent \pm 1 standard deviation. Ext = external, Int = internal. 
(a)

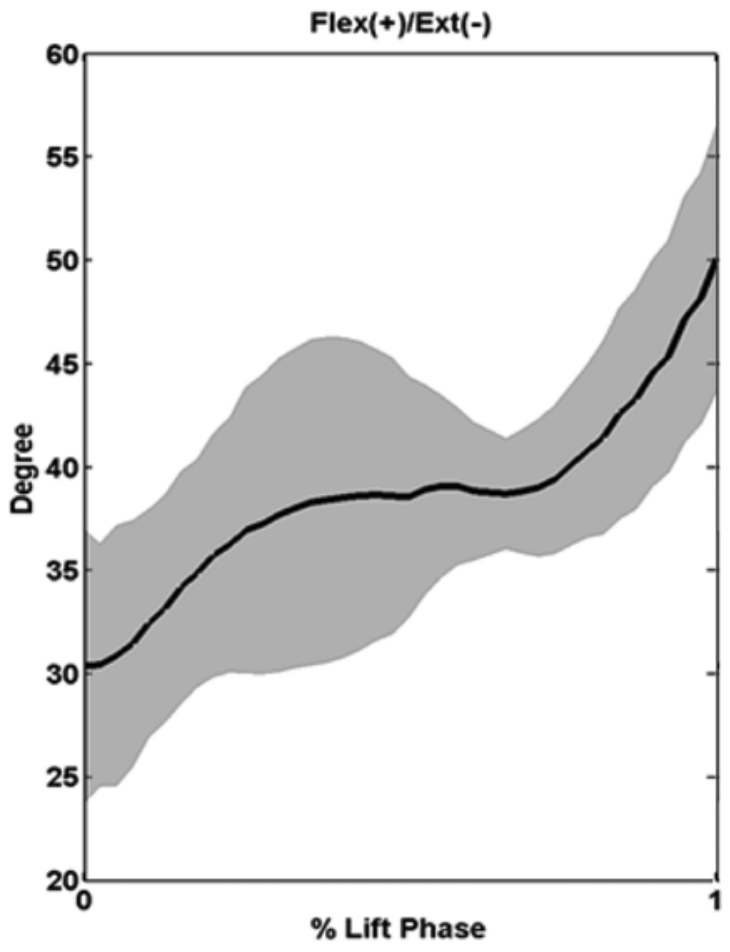

(b)

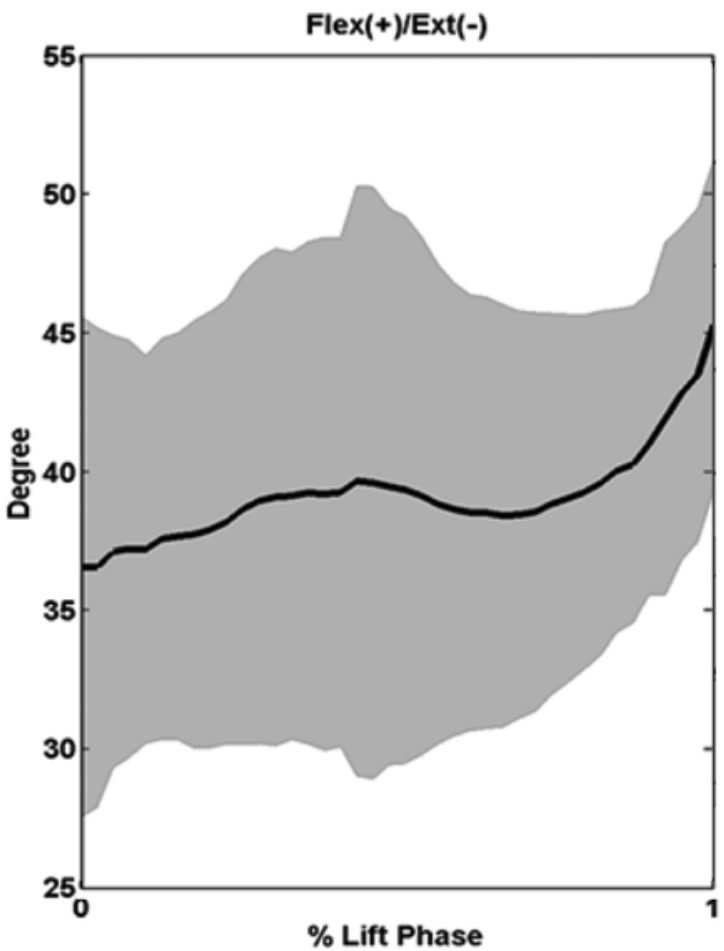

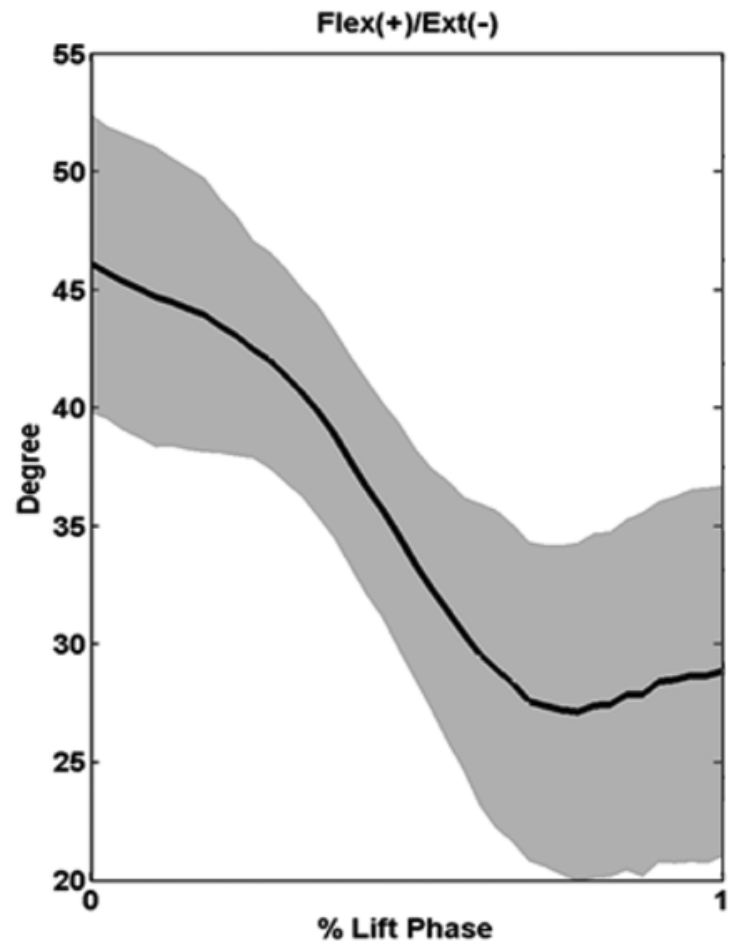

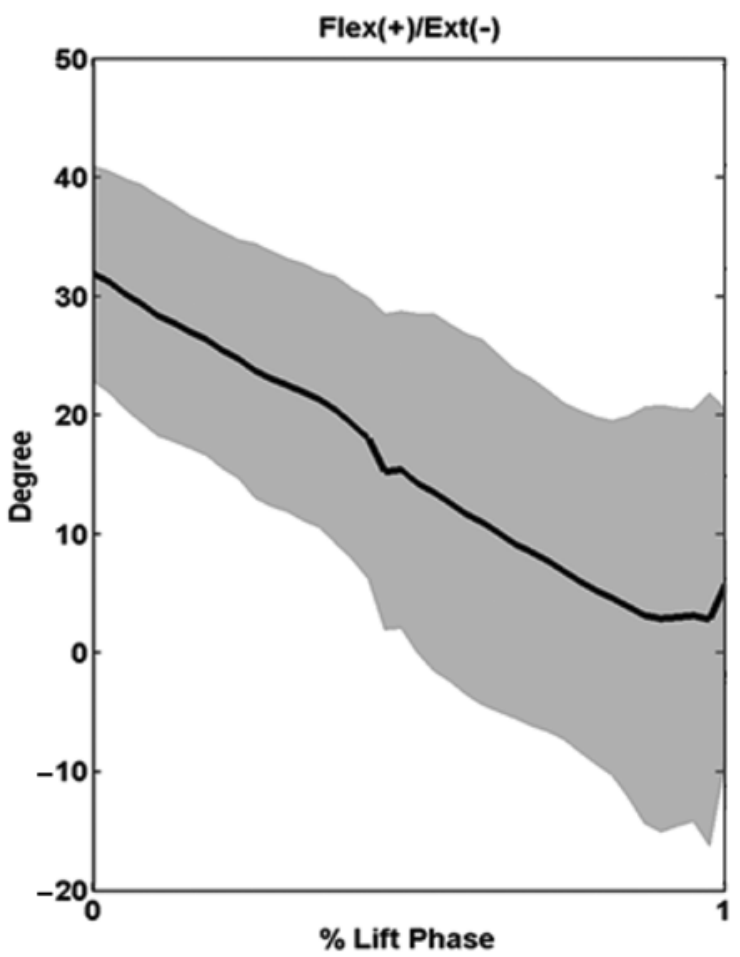

Figure 4.

Leading (left) and trailing (right) elbow flexion/extension range of motion of (a) all subjects with spinal cord injury and (b) all nondisabled subjects during lift phase of transfer. Solid lines correspond to group ensemble averages across trials, and shaded areas represent \pm 1 standard deviation. Ext $=$ extension, Flex = flexion. 
(a)

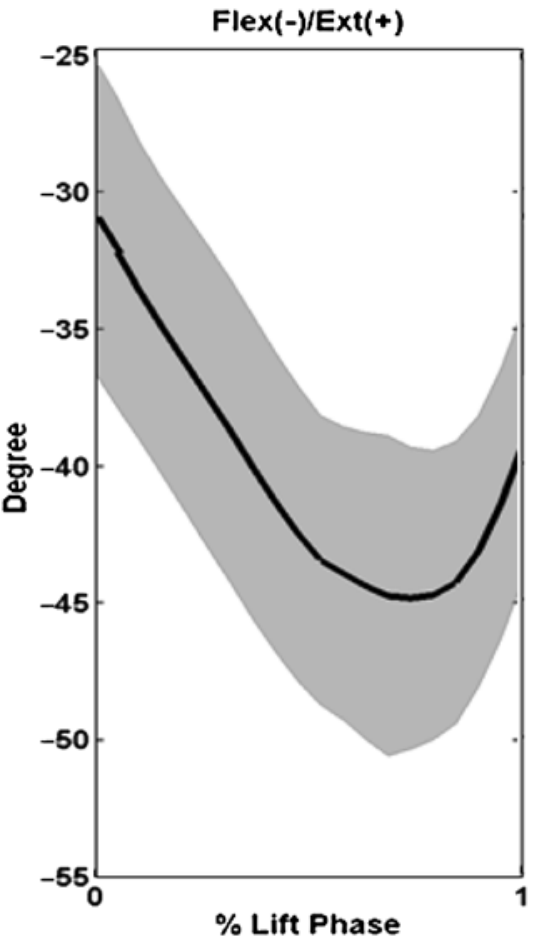

(b)

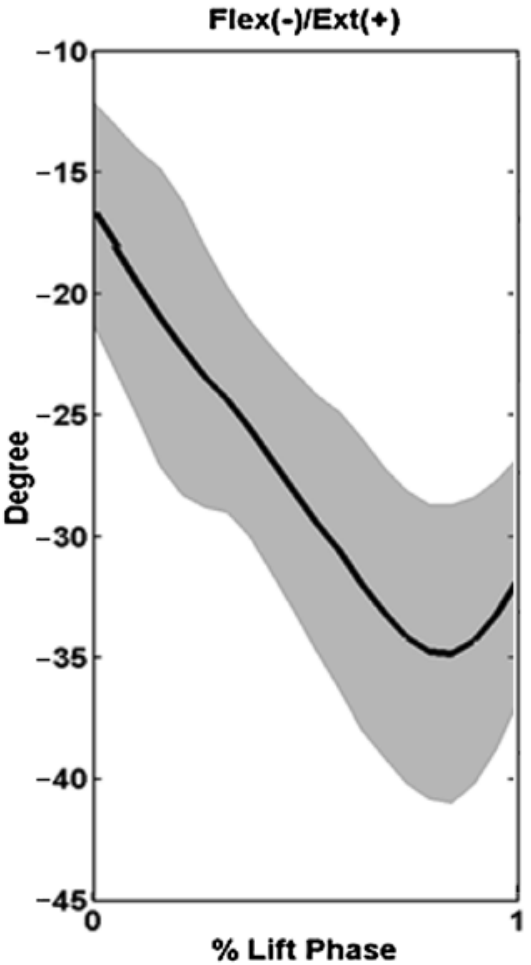

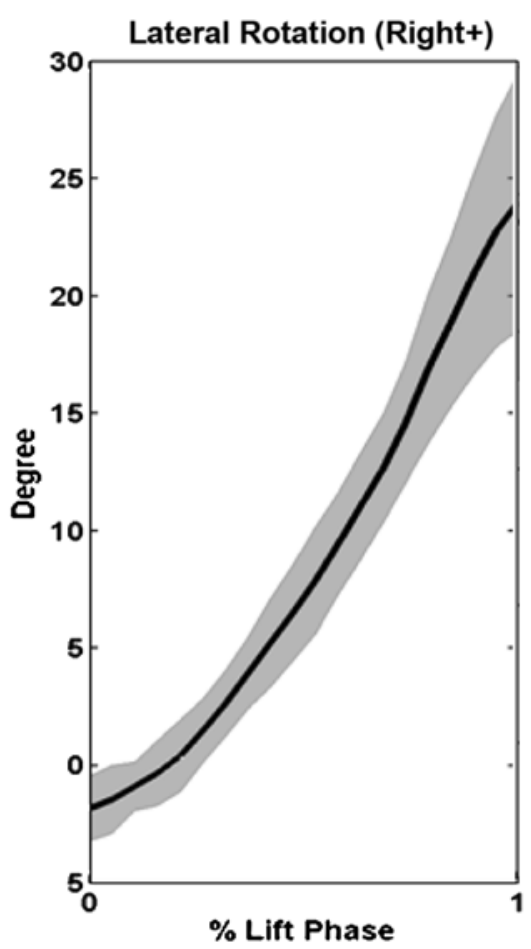
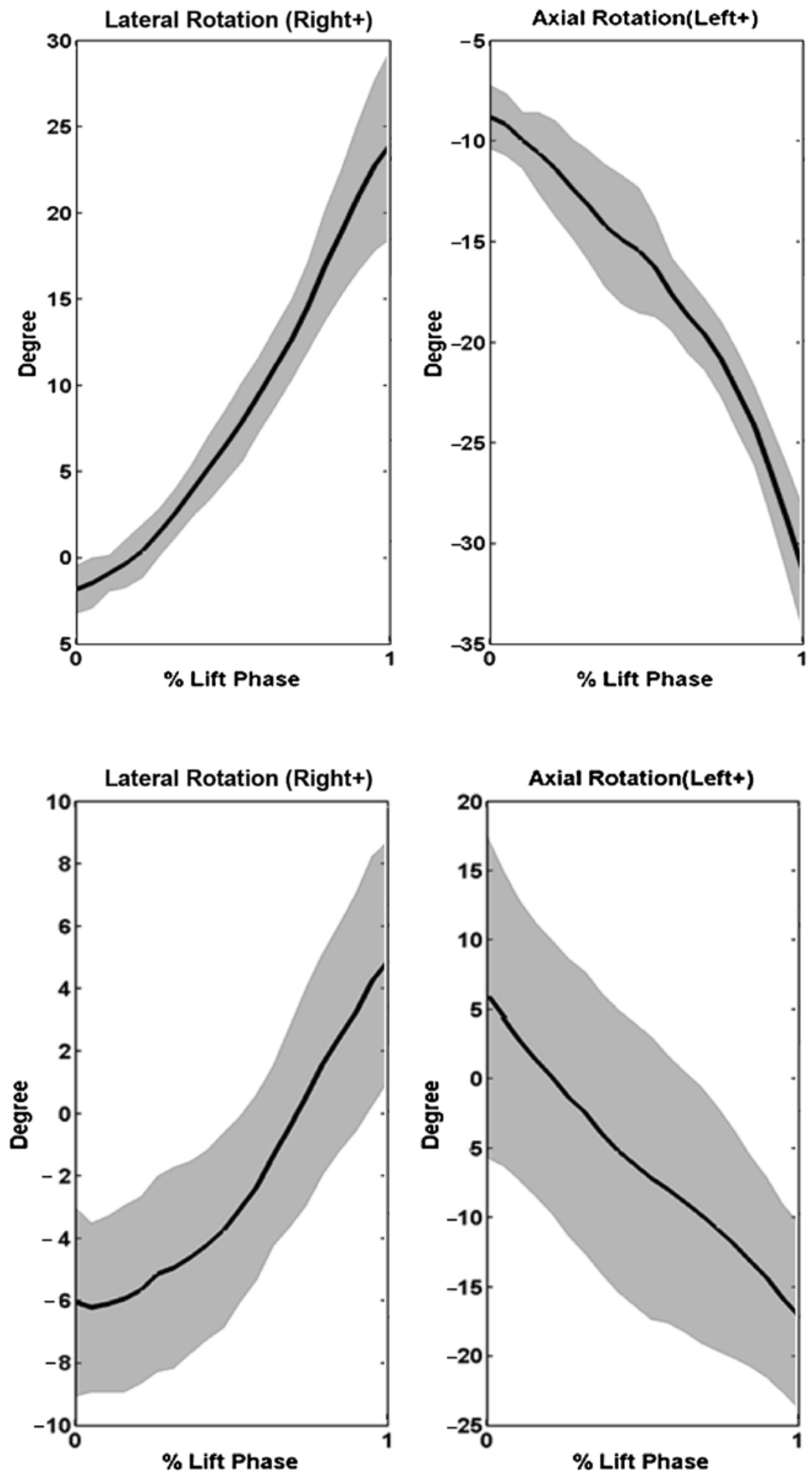

Figure 5.

Trunk range of motion for (a) all subjects with spinal cord injury and (b) all nondisabled subjects during lift phase of transfer. Solid lines correspond to group ensemble averages across trials, and shaded areas represent \pm 1 standard deviation. Ext $=$ extension, Flex $=$ flexion. 
For example, users often need to angle themselves and/or elevate their hips higher to clear the rear wheel when transferring from a wheelchair. Wide variability is reported in the way individuals orient their wheelchair with respect to the target surface [17]. Thus, systems that restrict the angle constrain the person from being able to set up for the transfer as they naturally would. Although our numbers were small, our system design accommodated a variety of wheelchair makes/models, sizes, and self-selected angles that ranged from $0^{\circ}$ to $45^{\circ}$. Future research should consider the factors that determine wheelchair orientation and their effects on upper-limb biomechanics.

Kinetic variables all showed moderate to excellent reliability, except for the peak anterior-posterior hand reaction forces in only the group with SCI for both the leading and trailing arms. The horizontal force components provide insight into the stabilization forces required to maintain dynamic postural balance when executing a transfer [13]. The balance deficits present in the group with SCI may have contributed to an inability to replicate the same stabilization forces over repeated trials. Future investigation is warranted with a larger sample size to determine if a relationship exists between repeatability of the kinetic measures and extensiveness of trunk impairment (e.g., high versus low levels of SCI). Overall, our results compare well with Gagnon et al. [13], who reported peak horizontal forces $\left(F_{\text {horizontal }}{ }^{2}=F_{x}{ }^{2}+F_{y}{ }^{2}\right)$ equal to 10.2 percent $\mathrm{BW}$ for the trailing hand and 8.8 percent BW for the leading hand, compared with approximately 16.0 percent $\mathrm{BW}$ and 11.4 percent $\mathrm{BW}$ for the trailing and leading hands in our study.

Kinematic variables were highly reliable in the group with SCI, suggesting that our subjects with SCI were experienced and able to adapt well to the novelty of the setup. Three of the shoulder variables exhibited low reliability in the nondisabled group and may be explained by the subjects' task naivety and lack of experience; however, their force application during transfer was highly consistent from trial to trial. The results may have been more repeatable had we taught the nondisabled subjects how to perform a sitting-pivot transfer and had they practiced before testing. We analyzed trial-to-trial reliability in part to determine the minimum number of trials necessary to obtain stable biomechanical measures of transfer performance. Based on the results of our study, we recommend a minimum of five transfer trials for data collec- tion involving kinetic and kinematic measures for future research studies.

Although we coached nondisabled subjects not to use their legs, the setup lacked the instrumentation necessary to determine whether they did and to what extent. Knowledge of the reaction forces at the feet for both groups would have allowed for a greater understanding of the load distribution through various parts of the body and the degree of weight-bearing through the legs. Since conducting this study, we have integrated a third force plate into our system to record feet reaction forces for future studies (seen near the front of the base platform in Figure 1).

\section{CONCLUSIONS}

A new transfer measurement system, described here in detail, was found to produce reliable and valid biomechanical data for the future study of sitting-pivot wheelchair transfers. Our system differs from others previously described in the literature in that it records forces when hand grasps are used, enables a variety of transfer scenarios to be mimicked by interchanging beams that vary in height and target surfaces, and permits subjects to be tested in their own wheelchair and setup with respect to the target surface. We found a majority of kinematic and kinetic measures to have excellent reliability during the lift phase of transfer. We recommended a minimum of five transfer trials for future studies to obtain a stable measure of a subject's transfer technique. Quantifying the mechanical demands of different types of wheelchair transfers will provide insight into the risk factors associated with the development of upper-limb pain and injury.

\section{ACKNOWLEDGMENTS}

\section{Author Contributions:}

Study concept and design: A. M. Koontz, M. L. Boninger, R. A. Cooper. Acquisition of data: P. Kankipati.

Analysis and interpretation of data: A. M. Koontz, Y. S. Lin, P. Kankipati. Drafting of manuscript: Y. S. Lin, A. M. Koontz.

Critical revision of manuscript for important intellectual content: A. M. Koontz, R. A. Cooper, M. L. Boninger.

Obtained funding: A. M. Koontz, M. L. Boninger, R. A. Cooper. Administrative, technical, or material support: A. M. Koontz, M. L. Boninger, R. A. Cooper.

Study supervision: A. M. Koontz. 
Financial Disclosures: The authors have declared that no competing interests exist.

Funding/Support: This material was based on work supported by the VA Rehabilitation Research and Development Service (grants E3589V, B3079R, and A4489R); the National Institute on Disability and Rehabilitation Research (grant NIDRR H133A011107); and the National Institutes of Health Center for Injury Research Control (grant NIH R49/CCR310285-06).

Institutional Review: This study was approved by the Department of Veterans Affairs Pittsburgh Healthcare System IRB.

Participant Follow-Up: Subjects who elect to receive the authors' newsletter or visit the authors' Web site will be informed of the publication of this study.

\section{REFERENCES}

1. Silfverskiold J, Waters RL. Shoulder pain and functional disability in spinal cord injury patients. Clin Orthop Relat Res. 1991;272:141-45. [PMID: 1934724]

2. Rintala DH, Loubser PG, Castro J, Hart KA, Fuhrer MJ. Chronic pain in a community-based sample of men with spinal cord injury: Prevalence, severity, and relationship with impairment, disability, handicap, and subjective wellbeing. Arch Phys Med Rehabil. 1998;79(6):604-14.

[PMID: 9630137]

DOI:10.1016/S0003-9993(98)90032-6

3. Bayley JC, Cochran TP, Sledge CB. The weight-bearing shoulder. The impingement syndrome in paraplegics. J Bone Joint Surg Am. 1987;69(5):676-78. [PMID: 3597466]

4. Van Drongelen S, Van der Woude LH, Janssen TW, Angenot EL, Chadwick EK, Veeger DH. Mechanical load on the upper extremity during wheelchair activities. Arch Phys Med Rehabil. 2005;86(6):1214-20. [PMID: 15954062] DOI:10.1016/j.apmr.2004.09.023

5. Allison GT, Singer KP, Marshall RN. Transfer movement strategies of individuals with spinal cord injuries. Disabil Rehabil. 1996;18(1):35-41. [PMID: 8932743] DOI:10.3109/09638289609167087

6. Allison GT, Singer KP. Assisted reach and transfers in individuals with tetraplegia: Towards a solution. Spinal Cord. 1997;35(4):217-22. [PMID: 9143083]

DOI:10.1038/sj.sc.3100393

7. Finley MA, McQuade KJ, Rodgers MM. Scapular kinematics during transfers in manual wheelchair users with and without shoulder impingement. Clin Biomech (Bristol, Avon). 2005;20(1):32-40. [PMID: 15567534] DOI:10.1016/j.clinbiomech.2004.06.011

8. Nawoczenski DA, Clobes SM, Gore SL, Neu JL, Olsen JE, Borstad JD, Ludewig PM. Three-dimensional shoulder kinematics during a pressure relief technique and wheelchair transfer. Arch Phys Med Rehabil. 2003;84(9):1293-1300.
[PMID: 13680564]

DOI:10.1016/S0003-9993(03)00260-0

9. Gagnon D, Nadeau S, Noreau L, Eng JJ, Gravel D. Trunk and upper extremity kinematics during sitting pivot transfers performed by individuals with spinal cord injury. Clin Biomech (Bristol, Avon). 2008;23(3):279-90.

[PMID: 18037198]

DOI:10.1016/j.clinbiomech.2007.09.017

10. Perry J, Gronley JK, Newsam CJ, Reyes ML, Mulroy SJ. Electromyographic analysis of the shoulder muscles during depression transfers in subjects with low-level paraplegia. Arch Phys Med Rehabil. 1996;77(4):350-55.

[PMID: 8607758$]$

DOI:10.1016/S0003-9993(96)90083-0

11. Wang YT, Kim CK, Ford HT 3rd, Ford HT Jr. Reaction force and EMG analyses of wheelchair transfers. Percept Mot Skills. 1994;79(2):763-66. [PMID: 7870500]

12. Gagnon D, Koontz AM, Mulroy SJ, Nawoczenski DA, Butler-Forslund E, Granstrom A, Nadeau S, Boninger ML. Biomechanics of sitting pivot transfers among individuals with a spinal cord injury: A review of the current knowledge. Top Spinal Cord Inj Rehabil. 2009;15(2):33-58. DOI:10.1310/sci1502-33

13. Gagnon D, Nadeau S, Noreau L, Dehail P, Gravel D. Quantification of reaction forces during sitting pivot transfers performed by individuals with spinal cord injury. J Rehabil Med. 2008;40(6):468-76. [PMID: 18509563] DOI:10.2340/16501977-0192

14. Tanimoto Y, Nanba K, Tokuhiro A, Ukida H, Yamamoto H. Measurement system of transfer motion for patients with spinal-cord injuries. IEEE Trans Instrum Meas. 2008; 57(1): 213-19. DOI:10.1109/TIM.2007.909501

15. Forslund EB, Granström A, Levi R, Westgren N, Hirschfeld H. Transfer from table to wheelchair in men and women with spinal cord injury: Coordination of body movement and arm forces. Spinal Cord. 2007;45(1):41-48. [PMID: 16670685]

DOI:10.1038/sj.sc.3101935

16. Gagnon D, Nadeau S, Desjardins P, Noreau L. Biomechanical assessment of sitting pivot transfer tasks using a newly developed instrumented transfer system among long-term wheelchair users. J Biomech. 2008;41(5):1104-10.

[PMID: 18191866]

DOI:10.1016/j.jbiomech.2007.11.021

17. Gagnon D, Nadeau S, Noreau L, Dehail P, Piotte F. Comparison of peak shoulder and elbow mechanical loads during weight-relief lifts and sitting pivot transfers among manual wheelchair users with spinal cord injury. J Rehabil Res Dev. 2008;45(6):863-73. [PMID: 19009472]

DOI:10.1682/JRRD.2007.11.0189

18. Monaghan K, Delahunt E, Caulfield B. Increasing the number of gait trial recordings maximises intra-rater reliability 
JRRD, Volume 48, Number 8, 2011

of the CODA motion analysis system. Gait Posture. 2007; 25(2):303-15. [PMID: 16730177]

DOI:10.1016/j.gaitpost.2006.04.011

19. Koontz AM, Cooper RA, Boninger ML, Souza AL, Fay BT. Shoulder kinematics and kinetics during two speeds of wheelchair propulsion. J Rehabil Res Dev. 2002;39(6):635-49. [PMID: 17943666]

20. Yavuzer G, Oken O, Elhan A, Stam HJ. Repeatability of lower limb three-dimensional kinematics in patients with stroke. Gait Posture. 2008;27(1):31-35. [PMID: 17257845] DOI:10.1016/j.gaitpost.2006.12.016

21. Wu G, Van der Helm FC, Veeger HE, Makhsous M, Van Roy P, Anglin C, Nagels J, Karduna AR, McQuade K, Wang X, Werner FW, Buchholz B; International Society of Biomechanics. ISB recommendation on definitions of joint coordinate systems of various joints for the reporting of human joint motion-Part II: Shoulder, elbow, wrist and hand. J Biomech. 2005;38(5):981-92. [PMID: 15844264] DOI:10.1016/j.jbiomech.2004.05.042

22. Veldpaus FE, Woltring HJ, Dortmans LJ. A least-squares algorithm for the equiform transformation from spatial marker co-ordinates. J Biomech. 1988;21(1):45-54. [PMID: 3339026$]$ DOI:10.1016/0021-9290(88)90190-X

23. Winter DA. Biomechanics and motor control of human movement. 2d ed. New York (NY): Wiley; 1990.

24. Gagnon D, Nadeau S, Gravel D, Noreau L, Larivière C, McFadyen B. Movement patterns and muscular demands during posterior transfers toward an elevated surface in individuals with spinal cord injury. Spinal Cord. 2005;43(2):
74-84. [PMID: 15356677]

DOI:10.1038/sj.sc.3101660

25. Landis JR, Koch GG. The measurement of observer agreement for categorical data. Biometrics. 1977;33(1):159-74. [PMID: 843571] DOI:10.2307/2529310

26. Sadowsky CL, McDonald JW. Activity-based restorative therapies: Concepts and applications in spinal cord injuryrelated neurorehabilitation. Dev Disabil Res Rev. 2009;15(2): 112-16. [PMID: 19489091] DOI:10.1002/ddrr.61

27. Cooper RA, VanSickle DP, Robertson RN, Boninger ML, Ensminger GJ. A method for analyzing center of pressure during manual wheelchair propulsion. IEEE Trans Rehabil Eng. 1995;3(4):289-98. DOI:10.1109/86.481968

Submitted for publication September 2, 2010. Accepted in revised form March 2, 2011.

This article and any supplementary material should be cited as follows:

Koontz AM, Lin YS, Kankipati P, Boninger ML, Cooper RA. Development of custom measurement system for biomechanical evaluation of independent wheelchair transfers. J Rehabil Res Dev. 2011;48(8):1015-28.

DOI:10.1682/JRRD.2010.09.0169

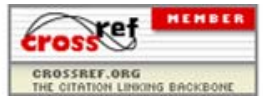

